\title{
HISTÓRIA E GÊNERO: UMA REFLEXÃO SOBRE A PRÁTICA DOCENTE E A HETERONORMATIVIDADE NO ENSINO FUNDAMENTAL, ANOS FINAIS
}

\author{
Zenildo Santos Silva ${ }^{1}$
}

RESUMO: Estudar gênero na escola torna-se importante, porque a luta pela igualdade ainda apresenta muitos desafios, a cultura patriarcal é predominante, fruto de um processo histórico, de perpetuação de comportamentos. Dessa forma, é inquietante saber de que maneira a prática pedagógica do professor de história pode contribuir para o combate à discriminação de gênero. Para isso, pretende-se analisar a importância das metodologias antissexistas, na construção de uma sociedade antimachista, ou seja, de que maneira a prática pedagógica do professor de história pode contribuir para combater a discriminação contra as diversas expressões de gênero. As discussões serão enriquecidas com: Bourdieu (2003), que trata da supremacia masculina; Butler (2003), com as discussões sobre heteronormatividade e controle; Fernandes (2005), que realiza debates sobre a prática docente; Foucault (1996), contribui com a teoria dos dispositivos de poder e Louro (2010), com as discussões sobre a prática docente, gêneros e os diversos discursos discriminatórios vigentes. A presente pesquisa é de cunho bibliográfico, ou seja, utilizará de diversas revisões literárias para exploração da temática, no viés qualitativo. Espera-se que com o presente artigo os professores de humanas, em especial história, reflitam sobre a atuação docente e criem novas praticas para a promoção do respeito a diversidade de gêneros.

Palavras - chave: Gênero. Heteronormatividade. Prática pedagógica.

ABSTRACT: Studying gender in school becomes important, because the struggle for equality still presents many challenges, the patriarchal culture is predominant, the result of a historical process of perpetuation of behaviors. Thus, it is disturbing to know how the pedagogical practice of the history teacher can contribute to the fight against gender discrimination. To this end, we intend to analyze the importance of antisexist methodologies, in the construction of an antimachist society, that is, how the pedagogical practice of the history teacher can contribute to combat discrimination against the various expressions of gender. The discussions will be enriched with: Bourdieu (2003), which deals with male supremacy; Butler (2003), with discussions about heteronormativity and control; Fernandes (2005), which holds debates on teaching practice; Foucault (1996), contributes to the theory of power devices and Louro (2010), with discussions about teaching practice, genres and the various discriminatory discourses in force. This research is of bibliographic nature, that is, it will use several literary revisions to explore the theme, in the qualitative bias. With this article, it is hoped that human teachers, in particular history, will reflect on teaching performance and create new practices to promote respect for gender diversity.

Keywords: Genre. Heteronormativity. Pedagogical practice.

\footnotetext{
${ }^{\mathrm{I}}$ Pós- graduado em Metodologia do Ensino de História Pelo Centro Universitário Leonardo Da Vinci. Gandu- Ba. Graduado em Psicologia e História, pela Faculdade de Ciências e Tecnologia FTC, zomocara@hotmail.com.
} 


\section{APRESENTAÇÃO}

As teorias heteronormativas são os critérios de normalidade estabelecidos no decorrer da história, ou seja, as construções de posições que impõe ao sujeito um sistema de valores morais aprisionado em uma maneira normativa de viver as questões sexuais. Os dispositivos de poder tiveram importantes efeitos, passaram a ser tomados como verdades.

Sendo assim, estudar gênero na escola torna-se importante, porque a luta pela igualdade ainda apresenta muitos desafios, pois a cultura patriarcal é predominante, fruto de um processo histórico, de perpetuação de comportamentos e das representações sociais dos papeis femininos e masculinos. Portanto, é essencial pensar em maneiras de desconstruir os mecanismos que fazem parte do senso comum, dos quais o imaginário social e cultural e os meios de comunicação estão impregnados, restringindo as possibilidades de cada pessoa desenvolver-se como sujeito.

Compreender tudo isso só faz ratificar a ideia de que as teorias educacionais e o conhecimento incorporado em sala de aula são controlados por princípios heteronormativos, produzindo uma educação sexista. Assim, tanto as escolas quantos os currículos são ferramentas ideológicas carregadas por tais princípios, sem questionar o androcentrismo presente na sociedade em geral.

Destarte, surge a seguinte problemática: de que maneira a prática pedagógica do professor de história pode contribuir para o combate à discriminação de gênero? Para responder tal questionamento, o presente trabalho terá como objetivo geral: analisar de que maneira a prática pedagógica do professor de história pode contribuir para combater a discriminação contra as diversas expressões de gênero. Como objetivos específicos: pretende-se compreender de que maneira os dispositivos de poder influenciaram na normatização da sociedade; conceituar heteronormatividade, e destacar a importância dos projetos pedagógicos nas aulas de história no combate de práticas heteronormativas.

Para realização dessa discussão, buscou-se uma interface com outras ciências humanas, como a pedagogia, sociologia, psicologia e filosofia, pois se entende que é preciso convidar, a todo o momento, a história para participar de forma mais intensa das questões ligadas ao gênero e à sexualidade. As discussões serão enriquecidas com o seguinte suporte teórico: Bourdieu (2003), que trata da supremacia masculina; Butler (2003), com as discussões sobre heteronormatividade e controle; Fernandes (2005), que realiza debates 
sobre a prática docente; Foucault (1996), que contribui com a teoria dos dispositivos de poder e Louro ( 2010 ), com as discussões sobre a prática docente, gêneros e os diversos discursos discriminatórios vigentes.

Assim, este estudo justifica-se pela relevância desse conhecimento para desconstrução da lógica heteronormativa que corrobora com arranjos sociais, conhecimentos e práticas de relações de poder marginalizadoras, dos sujeitos com comportamentos sexuais diferentes da norma. Por isso, é essencial que o professor contribua na problematização das novas construções de gênero, em uma perspectiva emancipatória e de caráter pluralista, mobilizando debates e projetos sobre a temática.

A metodologia empregada nos estudos consistiu na pesquisa em livros e bases de dados de elevado cunho e prestígio científico, tais como a Scielo (http://www.scielo.org) e o PubMed (https://www.ncbi.nlm.nih.gov/pubmed). Os descritores utilizados foram "história and gênero and sexualiade" e "sexualidade an norma and normas". Os referenciais teóricos selecionados foram as publicações que estavam disponíveis para download, escritas em português e que se enquadravam no escopo do estudo.

A presente pesquisa é de cunho bibliográfico, ou seja, utilizará de diversas revisões literárias para exploração da temática; qualitativa, pois não tem o intuito de obter números como resultados, mas entender qual o caminho para uma melhor reflexão da prática docente e sua relação com a heteronormatividade. Será utilizada a pesquisa exploratória, de natureza básica e narrativa, a qual agrega os referenciais sem a necessidade de uma busca sistemática, ampliando os conhecimentos sobre os assuntos e permitindo retificações e ratificações de informações.

O artigo está dividido em duas partes: na primeira será apresentado o conceito de dispositivos de poder e heteronormatividade, como elementos chave do entendimento das normas criadas no ocidente, para justificar comportamentos da discriminação sexista. $\mathrm{Na}$ segunda parte será enfatizada a importância dos projetos pedagógicos para o trabalho docente do professor de história, no combate a discriminação de gênero, práticas antimachistas e antissexista.

Todas essas questões estão atreladas a ideia de poder que é entendido como uma prática social constituída historicamente. Na visão de Foucault (1996), são formas díspares, heterogêneas, em constante transformação e está por toda parte, provocando ações e uma 
relação flutuante, não estando em uma instituição nem em ninguém, mas nas relações sociais existentes, sendo ações sobre ações, que vai além da dominação visível.

\section{HISTÓRIA E GÊNERO: UMA REFLEXÃO SOBRE A PRÁTICA DOCENTE E A HETERONORMATIVIDADE NO ENSINO FUNDAMENTAL, ANOS FINAIS}

Estudar gênero e práticas pedagógicas torna-se importante, porque a luta pela igualdade ainda apresenta muitos desafios, pois a cultura patriarcal é predominante, fruto de um processo histórico, de perpetuação de comportamentos e das representações sociais dos papeis femininos e masculinos. Por isso é essencial pensar maneiras de desconstruir os mecanismos que fazem parte do senso comum, dos quais o imaginário social e cultural e os meios de comunicação estão impregnados, restringindo as possibilidades de cada pessoa desenvolver-se como sujeito.

Ao observar a realidade cultural, busca-se entender as relações de poder entre gêneros, questionando assim as matrizes histórico-culturais, a naturalização de comportamentos, o patriarcado, a subordinação das mulheres. Ao questionar essas ordens, estruturas, é possível e necessário incluir outros marcadores nas discussões, como raça/etnia, classe, orientação sexual, entre outros, os quais geram mosaicos de marcadores geradores de sobreposição ao preconceito.

A cultura heterossexual pensa de si mesma como a forma elementar de associação humana, como o próprio modelo de relações entre gêneros, como a base indivisível de toda sociedade, e como os meios de reprodução sem os quais o mundo não iria existir. Na visão de Bourdieu (2003), a relação de dominação é vivida como natural pelos atores envolvidos, já que eles partilham dos mesmos esquemas de percepção, de avaliação e de ação. Esta relação não se dá de modo consciente e por isso mesmo não basta a conscientização acerca do fundamento da violência simbólica, é preciso transformar as estruturas sociais que produzem e reproduzem esses esquemas partilhados.

Os docentes serão o suporte na desconstrução do machismo, pois entende-se que sua contribuição consiste em problematizar os saberes necessários à docência, partindo do pressuposto de que o saber disciplinar, que diz respeito ao conteúdo a ser ensinado, é elemento necessário, mas não suficiente à profissão docente. Trata-se de compreender que o ato de ensinar não se reduz à sua dimensão técnica, pois ensinar é, obrigatoriamente, 
entrar em relação com o outro. Ora, para que essa relação se estabeleça, é preciso que o professor e os alunos se entendam minimamente, e essa compreensão perpassa por momentos de vivências e discussões de situações diárias (TARDIF, 2002).

Sendo assim, Louro (1997) ao entender que a construção do gênero é histórica e se faz cotidianamente, compreende-se que as relações entre os dois sexos, os discursos e as representações dessas relações estão em constante mudança. Isso supõe que as identidades de gênero estão continuamente se transformando. Para a autora, a escola continua imprimindo sua marca distinta sobre os sujeitos, através de múltiplos e discretos mecanismos. Por isso, os docentes necessitam observar o comportamento de alunos e alunas cobrados pela sociedade e de que maneira a regulamentação pune os que estão fora das normas, fazendo isso é possível pensar maneiras de desconstrução e conscientização para novas relações.

\section{I Apontamentos sobre heteronormatividade e diversidade sexual}

O termo heteronormatividade foi construído para definir as instituições e estruturas de compreensão que fazem a heterossexualidade ser vista não apenas como norma, mas também como o modelo privilegiado. Nesse viés, condutas sexuais que fogem à heterossexualidade são vistas como problemas sociais. Bourdieu (2003) apresenta a questão da normatização masculina principalmente a partir de uma perspectiva simbólica, destacando que a supremacia heterossexual seria uma forma específica de violência, por essa teoria, o autor entende o poder como dispositivo que impõe significações de forma legítimas, de maneira a dissimular as relações de força que sustentam as relações sociais.

Nessa circunstância, Bourdieu (2003) também contribui com o conceito de "libido social”, que para ele é um conjunto de forças que age sobre o sujeito em todos os momentos de seu desenvolvimento e que auxilia na aquisição de elementos necessários para a formação de atitudes, tanto num sentido da experiência individual quanto da esfera coletiva que será fundamental na classificação dos sujeitos quanto ao seu pertencimento de gênero e afiliação da sua sexualidade. A classificação de sexo, a partir de então, filtra as possibilidades de existência dos indivíduos, gerando tanto novas possibilidades quanto impossibilitando certos resultados num contexto de aquisição e manutenção das representações individuais e coletivas. 
$\mathrm{Na}$ visão de Butler (2003) há em nossa cultura, uma norma estabelecida que atravessa toda constituição, tanto das estruturas sociais, quanto das subjetividades. $O$ modelo da heterossexualidade como única forma possível da expressão da sexualidade seria, dessa maneira, um forte elemento de regulação. Para esta autora, o que entra em jogo nesse cenário é a própria definição de homem e a delimitação de que alguns corpos e vidas são mais legítimos que outros.

Para Salih (2012) Judith Butler está empenhada em questionar continuamente o sujeito, indagando em que processos estes existem, de que meios são construídos e como essas construções são bem sucedidas ou não. No contexto social da normatividade, as categorias do sexo e do desejo deveriam se manter em uma relação coerente, segundo os parâmetros estabelecidos pelo modelo. Porém, essa estabilidade não consegue se sustentar. Os corpos promovem a desordem nesse modelo criado para regulá-los, fazendo com que ele perca sua força normativa no campo da sexualidade.

Assim, Butler (2003) destaca que, a normatividade a partir de um duplo sentido, ora é uma correspondência social, um norte para as ações e relações sociais, ora diz respeito ao procedimento que normaliza e estabelece de forma coercitiva o desenvolvimento dos homens e das mulheres a partir dos modelos. Essas normas são responsáveis por governar a vida e definir os papéis sociais.

Butler (2003), ao definir o gênero como uma construção a partir de leis repressivas em corpos que se assumem como pré-discursivos, define a binaridade de gênero como um fator determinante para a construção de uma matriz heterossexual. Para ela, a instituição de uma heterossexualidade compulsória e naturalizada exige e regula o gênero como uma relação binária em que o termo masculino diferencia-se do termo feminino. Dessa maneira, a normatização da heterossexualidade é uma das responsáveis por manter a coerência da estrutura sexo, gênero e desejo.

Assim, a heterossexualidade compulsória, mais do que sustentar a opressão exercida sobre quem possui orientações sexuais diferentes da heterossexual, é responsável também por estruturar a opressiva diferenciação entre gêneros. A heterossexualização do desejo institui a produção de oposições discriminadas e assimétricas entre feminino e masculino, em que estes são compreendidos como atributos expressivos de macho e de fêmea. Sexo e gênero foram cristalizados sob a aparência de realidade ou um fato natural, o 
que permite o entendimento do mundo como uma hegemonia heterossexual (BUTLER, 2003).

Neste contexto, a heteronormatividade configura-se na premissa de que, por um fator natural, só existem machos e fêmeas e por isso a relação heterossexual é exata e dotada do poder de procriação. Assim, os gêneros ficam encaixados nas categorias de feminino e masculino e a pessoa dotada de um determinado sexo físico e outro "gênero incorrespondente" com tal sexo é considerada completamente fora da orientação sexual dita como normal.

Warner (1993), contribui com uma das primeiras definições de heteronormatividade na literatura. Segundo ele, o termo define um sistema que defende a heterossexualidade como única modalidade de vida existente, marginalizando quem se desvia desse padrão. Por meio dos artefatos das ciências, uma sociedade heteronormativa afasta os desejos e anseios de outras orientações sexuais. Neste âmbito, a heteronormatividade passa a ser o sistema que torna a sexualidade heterossexual como norma universal, corroborando com os discursos que descrevem a homossexualidade como desviante.

Nesse sentido, Barbero, (20II, p. 63) contribui:

A heterossexualidade se impõe, fundamentalmente, por meio do estabelecimento de ideais. Ideais sexuais positivos, que correspondem às expectativas relacionadas a ser homem ou mulher e negativos ligados à homossexualidade e outras variações do erotismo. A prática de relações homossexuais e outras variações eróticas diferentes das tradicionais, apesar de não ser proibida, é ainda considerada - popularmente - como anormal. O problema está em que não somente existem ideais abstratos; exercem-se, concretamente, muitos atos preconceituosos e violentos com relação aos comportamentos rejeitados.

A cultura heterossexual pensa de si mesma como a forma elementar de associação humana, como o próprio modelo de relações entre gêneros, como a base indivisível de toda sociedade, e como os meios de reprodução sem os quais o mundo não iria existir. A origem da imposição heterossexual insere-se a partir da descoberta do sexo biológico do bebê, pois nesse momento já se escolhe as roupas com cores socialmente atribuídas aos sexos, arruma-se o quarto e brinquedos de acordo com as atribuições sociais do que é para menino e para menina, tudo faz parte de um ritual inconsciente ou não que tem por objetivo afirmar a orientação sexual do indivíduo desde muito cedo (WARNER 1993).

Nessa perspectiva, a heteronormatividade se refere a como essa organização social oriunda da norma hetero é estendida para aqueles que não são heterossexuais. Se na 
heterossexualidade compulsória todas as pessoas que não são heterossexuais são consideradas doentes e precisam ser explicadas, estudadas e tratadas, na heteronormatividade elas tornam-se coerentes desde que se identifiquem com a heterossexualidade como modelo, isto é, mantenham a linearidade entre sexo e gênero (WARNER, 1993).

Verifica-se, assim, que o discurso heteronormativo cria os ideais sociais, construindo um padrão sexual normal na tentativa de direcionar a pulsão, o que não deixa de ser uma forma de controle. Tudo isso faz compreender que a dominação masculina obedece a uma lógica que torna possível a sua manutenção, em termos gerais, essa lógica diz respeito a um princípio simbólico conhecido e reconhecido tanto pelo dominante quanto pelo dominado, ou seja, a dominação só é possível quando o discurso do dominador é assimilado pelo dominado, quando o sujeito incorpora a forma como deve pensar e agir, imposta pelos dominadores (BOURDIEU, 2003).

Ainda na visão de Bourdieu (2003), a relação de dominação é vivida como natural pelos atores envolvidos, já que eles partilham dos mesmos esquemas de percepção, de avaliação e de ação. Esta relação não se dá de modo consciente e por isso mesmo não basta a conscientização acerca do fundamento da violência simbólica é preciso mais, é preciso transformar as estruturas sociais que produzem e reproduzem esses esquemas partilhados.

Essa incorporação é visível quando se focaliza as identidades sexuais e os discursos que circulam na sociedade sobre a homossexualidade dizem respeito à anormalidade, à doença e ao pecado. Quando o sujeito começa a tomar como seu esses discursos, ele passa a se sentir culpado por ser quem é, a não se aceitar e lutar contra um desejo visto como errado.

Assim, a ideia de masculinidade hegemônica é apresentada para proporcionar uma dinâmica de poder inscrita nas relações de gênero. Esse conceito está pautado no patriarcalismo e na heterossexualidade, compreendida antes como uma consolidação ou uma permanência natural, do que uma construção de gênero possível de ser problematizada.

Butler (2003, p.16) conceitua heterossexualidade como "norma" e utiliza o termo "matriz" para designar: 
O modelo discursivo/epistemológico hegemônico da inteligibilidade do gênero, o qual presume que, para os corpos serem coerentes e fazerem sentido (masculinoexpresso macho, feminino-expressa fêmea), é necessário haver um sexo estável, expresso por um gênero estável, que é definido oposicional e hierarquicamente por meio da prática compulsória da heterossexualidade.

Assim, a heteronormatividade não perpassa apenas pela noção de padronização da sexualidade humana, que tem como modelo: práticas, atos e desejos sexuais do casal heterossexual, mas também, diz respeito à normatização e ao processo de naturalização dos corpos, comportamentos e identidades de gênero demarcado em campos femininos e masculinos construídos pela cultura e reconstruídos ao longo do tempo.

Saffioti (1997) assegura que existe uma violência de gênero, quando se retira os direitos humanos numa perspectiva de manutenção das desigualdades hierárquicas existentes para garantir obediência, subalternidade de um sexo a outro. Trata-se de forma de dominação permanente e acontecem em todas as classes sociais, raças e etnias.

Observadas sob uma perspectiva histórica e de totalidade, a opressão e exploração das mulheres pode ser percebidas não como destino natural, mas como construção social que pode, inclusive, ser desconstruída. Essa perspectiva implica a consideração de que as significações atribuídas ao masculino e ao feminino são desenvolvidas na sua interface

com relações sociais mais amplas, na mudança de pensamento, oportunizado também pela escola.

Nesta linha de reflexão, Louro (2010), defende que são os processos culturais que definem o que é ou não natural. Para a autora, o individuo é um ser social que, por meio de processos culturais, produz e transforma a natureza e a biologia, tornando-as históricas; e, assim, os corpos ganham sentido socialmente, isto porque a inscrição dos gêneros, feminino ou masculino, nos corpos é feita, no contexto de uma determinada cultura e, portanto, com as marcas dessa cultura. As possibilidades da sexualidade, das formas de expressar os desejos e prazeres, também são sempre socialmente estabelecidas e codificadas. As identidades de gênero e sexuais são, portanto, compostas e definidas por relações sociais moldadas pelas redes de poder de uma sociedade.

\subsection{As aulas de história no combate ao machismo e sexismo}

Nos últimos anos, principalmente a partir do final da década de 1970, a produção historiográfica brasileira passou por profundas mudanças conceituais e epistemológicas, 
resultando em grande parte das novas tendências calcadas na Nouvelle Histoire e na História Social Inglesa, que elegeram como objeto de estudo temas relativos ao cotidiano, à vida privada, às mentalidades coletivas, ao imaginário e às representações sociais de segmentos até então desprezados pela historiografia tradicional (FERNANDES, 2005).

Essa mudança teórico-metodológica se fez sentir, também, no âmbito das práticas pedagógicas com a introdução de novos temas e objetos de pesquisa, a saber: a história do ensino e a constituição das disciplinas escolares, o livro escolar e as práticas de leitura, as questões relacionadas ao gênero, à infância e aos grupos étnicos (FERNANDES, 2005).

Conforme Pacheco (2005), inserir a questão de gênero como categoria de análise no currículo do componente curricular História passa pelo entendimento de que existe uma dificuldade conceitual sobre o significado de currículo e de gênero, amparada na sua complexidade, o que torna a tarefa complicada alertando sobre a atual emergência do campo de estudos sobre currículo como um dos complicadores que afetam a sua conceituação, impedindo um acordo sobre o que realmente significa.

A verdade é que a motivação para o conteúdo gênero ainda tem um percurso a ser trilhado no sentido de vir a também fazer parte da formação docente. Contudo, a reação e interação das mulheres assim como as revelações expressas nos depoimentos mostram o despertar de uma visão mais crítica das próprias concepções no que diz respeito às relações de gênero, levando-as a compreender os limites historicamente impostos às mulheres, assim como a importância de estabelecer que a criação das identidades configura-se nas relações sociais entre o feminino e masculino, nos diversos contextos que as interações acontecem. É um processo contínuo, dinâmico de construção e de reconhecimento de si na condição de sujeito ativo da construção da história.

As Diretrizes Curriculares Nacionais abordaram de maneira tímida a questão da diversidade e do gênero no ensino fundamental, tanto para $\mathrm{I}^{\circ}$ ao $5^{\circ}$ anos, como para $6^{\circ}$ a $9^{\circ}$ 은 anos, ocupando uma parte dos componentes relacionados a temas transversais, sendo que essa questão foi abordada de maneira sucinta em uma parte complementar aos Parâmetros Curriculares Nacionais - PCNs. O documento propõe que a sexualidade e os papéis sociais façam parte das aulas de todos componentes curriculares, para que os estudantes compreendam as diversas transformações relacionadas as identidades sociais e mudanças biológicas, deixando as questões de gênero longe das discussões. 
Já a Base Nacional Comum Curricular (2017) motiva as atividades pedagógicas articuladas às diferentes culturas, identidades, diversidades com vistas na formação da integralidade do ser. A BNCC entende que é papel da escola ensinar a pensar e provocar discussões reflexivas sobre as questões contemporâneas que afligem a vida de todos. Nesse contexto, a função da educação é oportunizar a reflexão sobre as questões de gênero, raça, identidade e indicar a existência da diversidade sexual, de forma que todos sejam agregados.

Por isso, é significativo repensar os currículos, criticando seu androcentrismo e tendências sexistas através de oficinas didáticas e projetos pedagógicos em diferentes momentos letivos. Assim sendo, compreende-se melhor todas as implicações sociais no estudo da História em sala de aula, quebrando paradigmas machistas, profundamente enraizado nas práticas sociais. A ênfase aqui é dada ao ensino fundamental, anos finais, principalmente porque da faixa etária dos alunos, que por estarem na adolescência começam a enfrentar os dilemas da sexualidade e da compreensão de si e do outro.

Isso se torna importante porque estudar História vai além de conhecer ou memorizar fatos e acontecimentos. A aprendizagem dos aspectos históricos leva o educando a compreender sua própria construção enquanto protagonista, fruto do processo histórico de constituição da sociedade, das relações de trabalho e de poder, podendo diante desse conhecimento, modificar seu contexto. Tal compreensão leva a formulação de ideias em determinado tempo e espaço, de forma que as comparações entre passado e presente, proporcionem reflexões através das quais se podem propor mudanças significativas.

O Plano Nacional de Educação (PNE) aprovado em 2014, responsável por definir metas para o período de dez anos do Ensino Básico ao Superior, buscou lutar contra a discriminação ao promover a equidade de gênero e difundir propostas pedagógicas sobre sexualidade (BRASIL, 20I4). Contudo, docentes de história ainda precisam repensar e explorar os aspectos das relações sociais que têm sido negados dentro de perspectivas heteronormativas, pois enquanto sociedade interioriza-se as concepções de gênero dominante, desenvolvendo, desta forma ambiguidades e conflitos que as experiências de outros e outras trazem.

E a BNCC, Base Nacional Curricular Comum, comunga dessa ideia quando destaca: 
Ao longo de toda a Educação Básica, o ensino das Ciências Humanas deve promover explorações sociocognitivas, afetivas e lúdicas capazes de potencializar sentidos e experiências com saberes sobre a pessoa, o mundo social e a natureza. Dessa maneira, a área contribui para o adensamento de conhecimentos sobre a participação no mundo social e a reflexão sobre questões sociais, éticas e políticas, fortalecendo a formação dos alunos e o desenvolvimento da autonomia intelectual, bases para uma atuação crítica e orientada por valores democráticos. (BRASIL, 2018, p.358).

Esses valores democráticos citados pela Base perpassam pelo respeito à diversidade, ou seja, as diversas expressões identitárias, inclusive de gênero. A desconstrução desses comportamentos representa uma forma de resistência buscada por meio de linhas subterrâneas, para significar uma aproximação da história de mulheres e homens e para repensar processos de exclusão na história oficial.

A ideologia heteronormativa reduz o outro a si mesmo, que nem sequer coloca a questão da contribuição dos diferentes como importante. As questões históricas transmitidas ao longo do tempo sofrem com as convenções e relações de poder que operam recortes objetos de conhecimento a serem ensinados, seja nas aulas rotineiras, seja por meio de projetos pedagógicos.

Existem várias definições sobre a pedagogia de projetos, a que se aproxima dos objetivos dessa proposta é a do projetar, isto é, lançar-se, sair de onde se encontra em busca de novas soluções. O uso de projetos constitui uma das posturas metodológicas de ensino mais dinâmica e eficiente, sobretudo pela sua força motivadora e aprendizagens em situação real, de atividade globalizada e trabalho em cooperação. No projeto todos passam a ser protagonistas, os resultados sempre são fruto de uma caminhada coletiva.

De acordo com Leite (1996, p.24):

Ao participar de um projeto, o aluno está envolvido em uma experiência educativa em que o processo de construção de conhecimento está integrado às práticas vividas. Esse aluno deixa de ser, nessa perspectiva, apenas um aprendiz do conteúdo de uma área de conhecimento qualquer. É um ser humano que está desenvolvendo uma atividade complexa e que nesse processo está se apropriando, ao mesmo tempo, de um determinado objeto do conhecimento cultural e ser formado como sujeito cultural.

O interessante é que a pedagogia de projetos demonstra que a educação deve romper as barreiras do tradicional, através de métodos que agregam vários componentes curriculares e conhecimentos, de forma interdisciplinar. A atividade com projetos significa repensar o ambiente escolar, sua maneira de lidar com assuntos das áreas de conhecimento 
e, também, uma nova forma de posicionar os alunos no desenvolvimento diário das atividades propostas.

A sala de aula é o espaço privilegiado de socialização das inúmeras questões nas quais está o gênero, hoje presente de modo explícito ou velado nos arranjos curriculares. Neste sentido, nas aulas de história e, em diversos momentos do ano letivo, por meio de oficinas e projetos didáticos há uma extrema necessidade de sensibilizar para a quebra de padrões, tradições determinados pelo sexo e pelo poder patriarcal. É importante lembrar que essa tarefa não se realiza apenas em um projeto ou oficina, são ações contínuas que precisam fazer parte da rotina escolar.

Se o papel da educação não se reduz à transmissão formal de conhecimentos, mas de vivências cidadãs, cabe à escola contribuir para a construção de uma sociedade mais justa e digna, e isso perpassa pelo respeito. Nesse sentido, a BNCC, área de ciências humanas acrescenta:

As Ciências Humanas devem, assim, estimular uma formação ética, elemento fundamental para a formação das novas gerações, auxiliando os alunos a construir um sentido de responsabilidade para valorizar: os direitos humanos; o respeito ao ambiente e à própria coletividade; o fortalecimento de valores sociais, tais como a solidariedade, a participação e o protagonismo voltados para o bem comum; e, sobretudo, a preocupação com as desigualdades sociais. (BRASIL, 2018: p.360).

O uso dos projetos e oficinas didáticas contribui muito na construção dessa consciência. $\mathrm{Na}$ visão de Valente (1999) na pedagogia de projetos, o aluno aprende no processo de produzir, levantar dúvidas, pesquisar e de criar relações, que incentivam novas buscas, descobertas, compreensões e reconstruções de conhecimento. Esses momentos são primordiais para criar situações de aprendizagem, cujo foco incide sobre as relações que se estabelecem, cabendo ao mediador realizar as intervenções necessárias para que o estudante possa encontrar sentido naquilo que está aprendendo.

Em síntese, no desenvolvimento do projeto, o professor pode trabalhar com diferentes tipos de conhecimentos que estão imbricados e representados em termos de três construções: procedimentos e estratégias de resolução de problemas, conceitos disciplinares e estratégias e conceitos sobre aprender.

A prática com projetos requer mudança na concepção de ensino e aprendizagem e, consequentemente, na visão do educador. Hernández (1998) afirma que o trabalho por projeto não deve ser visto como uma opção puramente metodológica, mas como uma 
maneira de repensar a função da escola, logo dos problemas sociais. Essa compreensão é fundamental, porque aqueles que buscam apenas conhecer os procedimentos, os métodos para execução de projetos, acabam se frustrando, pois não existe um modelo que dê conta da complexidade que envolve a realidade educacional.

Dessa maneira, trabalhar com projetos sobre gênero é levar em conta também a história feminina e diversas expressões sexuais. No Brasil, anos I970, sobretudo a partir da mudança na História Cultural, foi a época que se intensificaram os estudos sobre a condição feminina, questionadores da visão da mulher como um ser pertencente ao espaço privado da casa e da família. Esses estudos possibilitaram a compreensão de que as relações entre homens e mulheres são construídas historicamente (BRESCIANI, 1989).

As primeiras pesquisas depararam-se com a dificuldade de encontrar fontes históricas nas quais a mulher pudesse ser percebida através de sua própria voz. A maioria dos registros históricos sobre as mulheres, conhecidos até então, eram de autoria de homens. Isto é, eram olhares dos homens sobre as mulheres. Para conhecer mais sobre a mulher como sujeito histórico, é preciso ultrapassar os limites dos arquivos que a silencia e a torna invisível, arquivos frutos de procedimentos de registro que traduzem o olhar de homens sobre homens. Assim sendo, para visibilizar a mulher na História, é importante buscar a memória feminina em diferentes fontes históricas, muitas vezes quase sempre pouco tradicionais (BRESCIANI, 1989).

Dessa forma, ao repensar as questões de gênero, o sistema de ensino contemporâneo poderá reconhecer o protagonismo feminino, a variedade de identidades e culturas que coexistem em seu cotidiano, permitindo o trabalho com a construção do senso de relatividade do conhecimento. Também a partir da compreensão histórica das relações de gênero, o educador pode redimensionar sua prática questionando a importância de determinados assuntos, e o próprio conceito de conteúdo, refletindo sobre sua compreensão sobre o passado e sobre sua relação com o planejamento e os diversos recursos.

Em síntese, trabalhar com todas essas questões é de fundamental importância porque a desigualdade de gênero é uma realidade no Brasil, responsável pelos grandes números de feminicídios, estupros, homofobia e violências, que são historicamente justificadas e aceitas com naturalidade por muitos, tornando-se assim um grande desafio e um grave problema social que inviabiliza o cumprimento efetivo dos direitos humanos. 


\section{CONSIDERAÇÕES FINAIS}

Historicamente, existi a ideia de que um sexo detém o poder sobre o outro, nessa lógica cabe ao homem dominar, e a mulher obedecer, se aquele não se enquadra no perfil do macho provedor, está fora da normalidade, ficando na condição de escora social. Para reverter esse quadro é necessário considerar maneiras de socializar a contribuição dos diferentes gêneros para a história, isso possibilitaria uma maior visualização do problema e despertaria novas práticas para diminuir atitudes machistas.

Socialmente a visão machista "heteronormativa", é encarada com naturalidade e muitas vezes percebida, e tida como uma situação irrelevante sem necessidades de interferências e reflexões sobre determinadas posturas sexistas. A escola, por vezes, acaba também por transmitir, ainda que de maneira sutil, a ideologia de pensamento e atitudes dominantes na sociedade, quer através das relações que nela se estabelecem, quer pela transmissão formal de conteúdos curriculares e materiais didáticos sujeitos a uma perspectiva machista, que fortalecem uma supremacia de gênero. Assim, o sistema de ensino acaba por moldar, e disciplinar os indivíduos de acordo com os padrões impostos pela sociedade.

A heteronormatividade encontra-se presente no cotidiano escolar através de algumas ações como as linguagens nos livros, nos currículos escolares historicamente selecionados, nas atitudes dos docentes e dos estudantes, na diferenciação de papéis de gênero em atividades nas aulas de educação física, que de forma muito singular acabam por reforçar as diferenças e desfavorecer a igualdade de gêneros.

E os professores de história e de todas os componentes curriculares necessitam mudar essas questões criando projetos que quebrem com discursos arraigados na sociedade, muitas vezes naturalizados, legitimados de forma imperceptível, pois a sociedade reforça os estereótipos, e acabam distanciando homens e mulheres nas suas diversas singularidades.

Assim, o sistema de ensino necessita está atento ao cumprimento de sua função social, que além de comprometida com a formação cognitiva, agora também se compromete com as competências socioemocionais. Se a escola não intervier na visão estereotipada, estará permitindo que a cultura machista reproduza os esquemas e modelos de seu meio. 


\section{REFERÊNCIAS}

BARBERO, Graciela Haydée. A despatologização da orientação sexual: $O$ papel da Resolução oı/99 e o enfrentamento da homofobia. IN: Conselho Regional de Psicologia da 6a Região. Psicologia e diversidade sexual. São Paulo: CRPSP, Caderno Temático II, p. 6o68, 20II.

BOURDIEU, Pierre. A dominação masculina. Rio de Janeiro: Bertrand Brasil, 2003.

BRASIL. Diretrizes Curriculares Nacionais para a Educação. Brasília, MEC/SEF/COEJA, 2ooo.

. Base Nacional Comum Curricular: Educação Infantil e Ensino Fundamental. Brasília: MEC/Secretaria de Educação Básica, 2018.

SECRETARIA DA EDUCAÇÃO FUNDAMENTAL. Parâmetros Curriculares Nacionais: pluralidade cultural e orientação sexual. 2 ed. Rio de Janeiro: DP\&A, 2000 .

- Plano Nacional de Educação (PNE), 2014. Disponível em: http://www.planalto.gov.br/ccivil_03/_ato201I-2014/2014/lei/lizo05.htm. Acesso em: o5 de maio 2019.

BRESCIANI, Maria Stela (org.) Revista Brasileira de História . no․ I8 - SP ANPUH/Marco Zero - 1989.

BUTLER, Judith. Problemas de gênero: feminismo e subversão da identidade. Rio de Janeiro: Civilização Brasileira, 2003.

FERNANDES, José Ricardo Oriá. O livro didático e a pedagogia do cidadão: $O$ papel do Instituto Histórico e Geográfico Brasileiro no ensino de História. Saeculum - Revista de História [13]; João Pessoa. Jul/dez.2005. Disponível em: www.cchla.ufpb.br/saeculum/saeculumi3_arto9_fernandes.pdf acessado em 20 de abril de 2019.

FOUCAULT, Michel. Microfísica do Poder. Rio de Janeiro: Graal, 1996.

HERNÁNDEZ, F. Transgressão e mudança na educação: os projetos de trabalho. Porto Alegre: ArtMed, 1998.

LEITE, Lúcia Helena Alvarez. Pedagogia de Projetos: intervenção no presente. Presença Pedagógica, Belo Horizonte: Dimensão, 1996.

LOURO, Guacira Lopes. O corpo educado: pedagogias da sexualidade. Belo Horizonte: Autêntica, 2010. 
PACHECO, J. A. Estudos curriculares: para a compreensão crítica da educação. Porto: Porto Editora, 2005.

SAFFIOTI, Heleieth Iara Bongiovani. Violência de Gênero - lugar da práxis na construção da subjetividade. In: Revista Lutas Sociais, no 2, PUC/SP, 1997, pp.59-79.

SALIH, Sara. Judith Butler. Teoria queer. Trad. Guacira Lopes Louro. Belo Horizonte: Autêntica Editora, p. 235, 2012. SCOTT, Joan. "Gênero: uma categoria útil de análise histórica". In: Revista Educação e Realidade, v. 15. n. 2. Porto Alegre: 1990;

TARDIF, Maurice. Saberes docentes e formação profissional. Petrópolis, RJ: Vozes, 2002.

VALENTE, J.A. Formação de Professores: Diferentes Abordagens Pedagógicas. In: J.A. Valente (org.) O computador na Sociedade do Conhecimento. Campinas, SP: UNICAMP-NIED, 1999 .

WARNER, Michael. Fear of a Queer Planet: Queer Politics and Social Theory. Minneapolis/London, University of Minnesota Press, 1993. Disponível em: <https://uniteyouthdublin.files.wordpress.com/2015/or/michael-warner-ed-fear-of-aqueer-planet-queer-politics-and-socal-theory.pdf $>$. Acessado em: 26 ago. 2019; 